\title{
SELF-BURYING BEHAVIOR IN THE GENUS SICARIUS (ARANEAE, SICARIIDAE) ${ }^{1}$
}

\author{
By Jonathan Reiskind \\ Biological Laboratories, Harvard University
}

The family Sicariidae has only recently been recognized as a polyphyletic taxon. Although it is difficult to establish natural limits, Gertsch (1949) has more logically separated the group into the Scytodidae, Diguetidae, Plectreuridae, Loxoscelidae, and Sicariidae (s.s.), all of which had been subfamilies of the Sicariidae (Bonnet, 1945-1959). These five families are differentiated distinctly and naturally by their ethological characters. The sole reason for their being previously lumped is their common possession of simple genitalia. This character is automatically considered primitive and hence these spiders were "representative of the ancestral stock." Their genitalia may, indeed, be relatively unchanged from the primitive form but in many other characteristics these spiders are quite specialized and advanced and bear very little resemblance to the ancestral stock. One can readily talk of "primitive characters" but rarely of "primitive, living organisms."

Some of the highly specialized ethological characters of the families mentioned are:

Scytodidae: Prey captured by spitting gummy substance from chelicerae; egg cocoons carried; spiders sometimes live in web on stones and rocks or in houses (Dabelow, 1958).

Diguetidae: Tubular cocoon constructed from silk and detritus and suspended by web in vegetation over sheet web; layers of egg sacs in a cocoon which also acts as retreat for spider (Cazier \& Mortenson, I962).

Plectreuridae: Low lying mesh web, associated with tubular retreat under rock or debris, in which spider sometimes hangs up-sidedown; eggs in loose cocoon (W. Eberhard, pers. comm.; Gertsch, 1958).

Loxoscelidae: Large, irregular sheet web (hackled band appearance); eggs in loose sac.

\footnotetext{
${ }^{1}$ Research a by-product of National Institute of Health Grant No. AI01944 to Dr. H. W. Levi.

Manuscript received by the editor October 15, 1965.
} 
Sicariidae: No web, unique ethological specializations outlined below.

The family Sicariidae (s.s.) contains the single genus, Sicarius. The genus has a predominantly south temperate distribution with species also described from Peru, Chile, Argentina and Southern Africa, with single species found in eastern Brazil, the Galapagos Islands and Costa Rica. Merian (I9I3) states that this "distribution méridionale isolée est le résultat de la retraite de [ce genre], de la zone tropical vers le Sud." On biogeographic grounds Merian considers Sicarius part of an ancient fauna.

The simple genitalia in the Sicariidae place them in the ecribellate spider group known as the haplogynes. In regard to systematics, "spiders lacking distinctive genitalia, in particular the Haplogynae, tend to have been neglected rather than to have stimulated interest in extra-genital characters" (Cooke, 1965). These extra-genital characters must include aspects of the external morphology (as used in Cooke's study of Dysdera) as well as several non-morphological characters-e.g., ecological and ethological ones.

In order for a character to be taxonomically useful, whether morphological or not, it must be comparatively constant in the taxon being studied.

Sicarius exhibits three behavioral traits that are of potential systematic value:

I. Stridulation - When disturbed the spider will rub the femur of its pedipalp against ridges on the chelicerae, producing bee-like buzzing (Simon, 1893 of the South African species). Simon suggests that the buzzing frightens enemies.

2. Cocoon Construction - The structures built by an organism are the physical summation of certain behavioral patterns. In spiders these structures include webs and egg cocoons. As a hunting spider, Sicarius does not spin webs but constructs egg cocoons that are characteristically covered with an earthy coating. Simon ( I 899) utilized this ethological character in noting the difference in the cocoons of Sicarius hahni Karsch (S. W. Africa) and ? S. peruensis Keyserling (Peru).

3. Self-burying - This phenomenon, found in two species of South American Sicarius, is reported in this paper.

Two species of Sicarius collected by Dr. H. W. Levi in South America were used in this study. Because of an inadequate knowledge of the taxonomy of this genus I have designated by numbers the two distinct species discussed in this paper, and have so labelled the specimens and deposited them in the Museum of Comparative 
Zoology. Sicarius sp. I was collected under a log in a pasture near Santiago del Estero, Argentina, on April 2, 1965. Sicarius sp. 2 was found under a rock at the base of a loma in the desert south of Lima, Peru on February 7, 1965.

Detailed observations and timings were made by analyzing, frame by frame, $\mathrm{I} 6 \mathrm{~mm}$. motion pictures (24fps) of the complete, self-burying activity. Several runs of each species were analyzed and twelve frames from one take of Sicarius sp. I are presented in Plates I and 2.

The basic pattern of behavior observed was similar in both cases though the species are distinct. This pattern is outlined in Table I and illustrated in Figures $\mathrm{I}-\mathrm{I} 2$.

The first six steps (Table I) are invariable, qualitatively, though time duration of each action and period between actions varies a great deal. In digging, the first two pairs of legs dig while the hind pairs stabilize the spider (Fig. I). Positioning of legs (Step 6) varies from less than a second to four seconds.

Step 7 consists of the first pair of legs alternately throwing sand over the body and exposed portions of the 4th legs (arrow in Fig. 6) from 6-I 5 times (approx. 4 times/second). Tufts of hairs on abdomen (arrow in Fig. 2) aid in holding the sand-covering in place. In Sicarius sp. 2 this action is split into two sections. First the throwing of sand, then a pause of about 3O-I 20 seconds, then a continuation of

Table 1. Self-burying in Sicarius sp. 1 (duration in seconds, of each step within parentheses).

Step 1. Digs hole (1.0)

Step 2. Jumps into hole (0.2) Fig.

Step 3. Adjusts abdomen $(0.4)$

Step 4. Adjusts 4th legs (0.6) Fig. 3

Step 5. Buries 4th legs partly $(0.2)$

Step 6. Positions legs (2.0) Fig. 5

Step 7. 1st legs cover body and 4th legs with sand (1.8)

Step 8. Buries 1st legs partly $(0.6)$
Fig. 1 Fig. 6 Fig. 7
Step 9. 2nd left leg throws sand forward $(0.3) \quad$ Fig. 8

Step 10. Buries 2nd left leg $(0.5)$

Step 11. 2nd right leg throws sand forward (0.2) Fig. 9

Step 12. Buries 2nd right leg (0.6) Fig. 10

Step 13. 3rd left leg throws sand forward (0.2) Fig. 11

Step 14. Buries 3rd left leg (0.4)

Step 15. 3rd right leg throws sand forward (0.2)

Step 16. Buries 3rd right leg (0.4)

Figs. 1-6. Self-burying of Sicarius sp. 1, steps 1, 2, 4-7 (see Table 1 and text for details). 

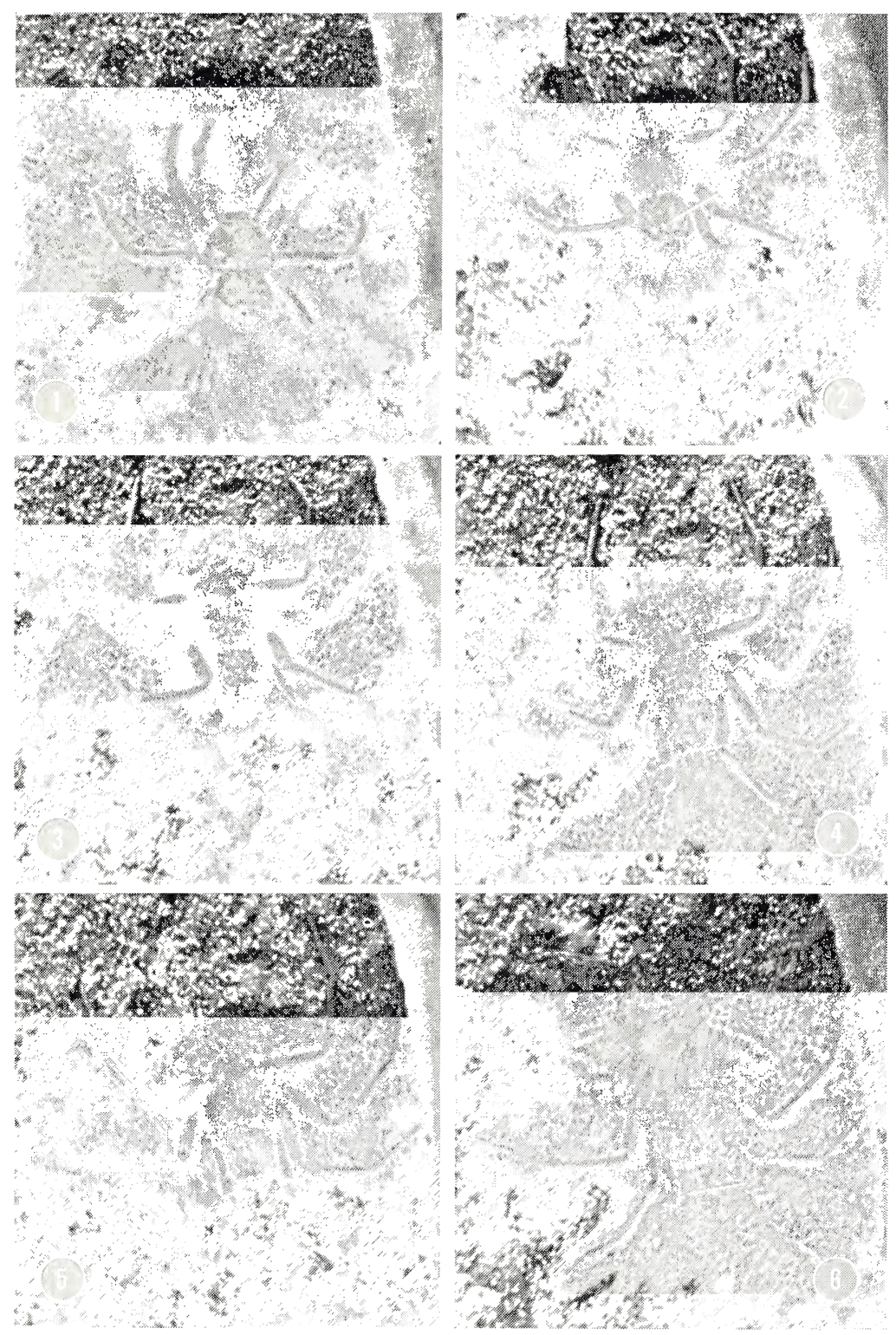

REISKIND - SICARIUS 

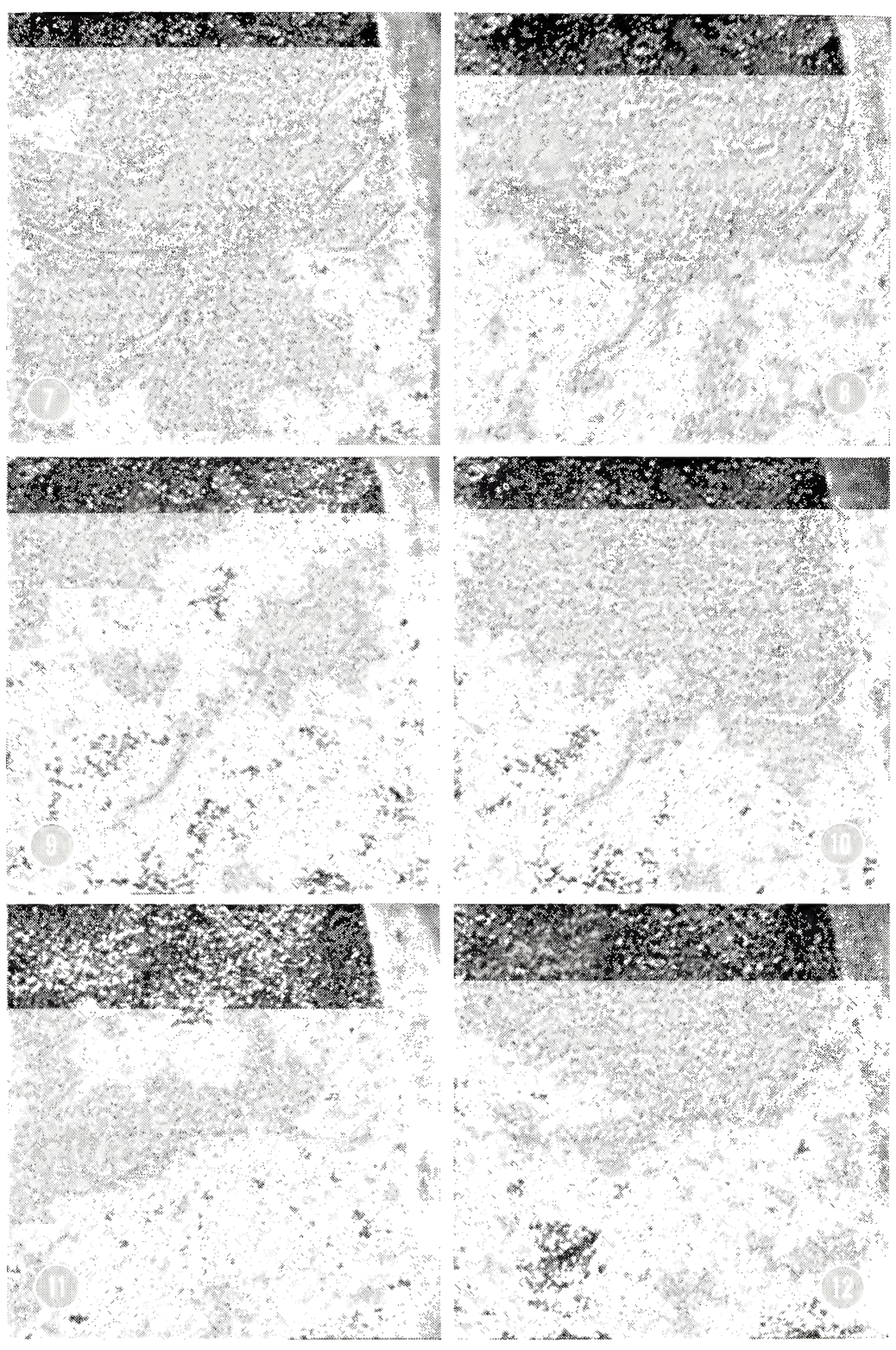

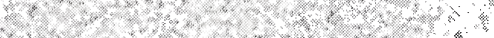
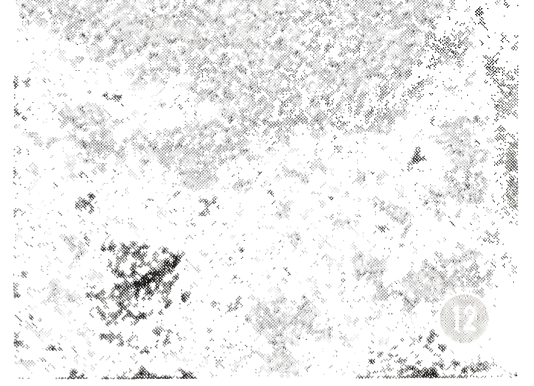

REISKIND - SICARIUS 
Step 7 or beginning of Step 8 . This same behavior is also observed in a more immature specimen of Sicarius sp. 2. In Sicarius sp. I there is usually no pause during Step 7 or between Steps 7 and 8 .

The first legs are buried (Step 8), as are the second and third legs, by forward, downward, jerky movements. Often the legs are only partially buried, leaving the patella and part of the femur exposed (arrows in Fig. 7).

Step 9 begins with either the right or left second leg (usually the right). After throwing sand forward, covering the exposed part of the first leg of its side, each leg buries itself (Steps 9-12).

The third leg actions (Steps I3-I6) resemble those of the second legs with either side beginning first. This usually completes the burying though there are often adjustments in the fourth legs, and sometimes fourth leg actions similar to the second and third legs.

The above description is of the complete, fixed behavior observed in both species of Sicarius. But often the burying stops prematurely, usually in response to some environmental difficulty - e.g., a cramped position or an unsatisfactorily dug hole. At other times cause of cessation before completion is unidentifiable.

To summarize, two species of Sicarius from South America show basically similar, fixed self-burying behavior with only one, distinct, qualitative difference (in Step 7). This fixed ethological character appears to be of potential systematic value.

The author wishes to thank Dr. H. W. Levi for suggesting this topic, collecting the organisms, and giving complete support in all phases of this work; Dr. W. K. Weyrauch for bringing this specific problem to notice: and both Drs. J. Abalos and P. Aquilar F. for invaluable aid in the field work.

\section{Explanation of Plate 17}

Figs. 7-12. Self-burying of Sicarius sp. 1, steps 8, 9, 10-12, 16 (see Table 1 and text for details).

\section{REFERENCES}

BonNeT, P.

1945-1959. Bibliographia Araneorum, Les Artisans de I'Imprimerie Douladoure, Toulouse.

Cazier, M. A. and M. A. Mortensen

1962. Analysis of the habitat, web design, cocoon and egg sacs of the tube weaving spider Diguetia canities (McCook). (Aranea, Diguetidae). Bull. So. Calif. Academy Sciences 61 (2) : 65-88. 
Cooke, J. A. L.

1965. Systematic Aspects of the External Morphology of Dysdra crocata and Dysdera erythrina (Araneae, Dysderidae). Acta Zoologica 46: 41-65.

DabelOW, S.

1958. Zur Biologie der Leimschleuderspinne Scytodes thoracica (Latreille). Zool. Jb. Syst. 86:85-126.

GerTsCh, W J.

1949. American Spiders. D. Van Nostrand Company, Inc. Princeton, New Jersey.

1958. The Spider Family Plectreuridae. Amer. Mus. Novitates No. 1920. Merian, P.

1913. Les Araignées de la Terre de Feu et de la Patagonie. Rev. La Plata $20: 7-100$.

Simon, E.

1893. Ann. Soc. Ent. France 62 Bull. ent.: CCXXIV-CCXXV.

1899. Note sur le cocon ovigère d'un sicarius du Pérou. Bull. Soc. Ent. France 1899 (19) : 367-368. 


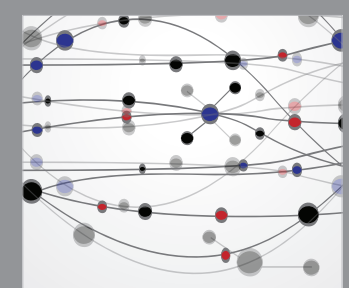

The Scientific World Journal
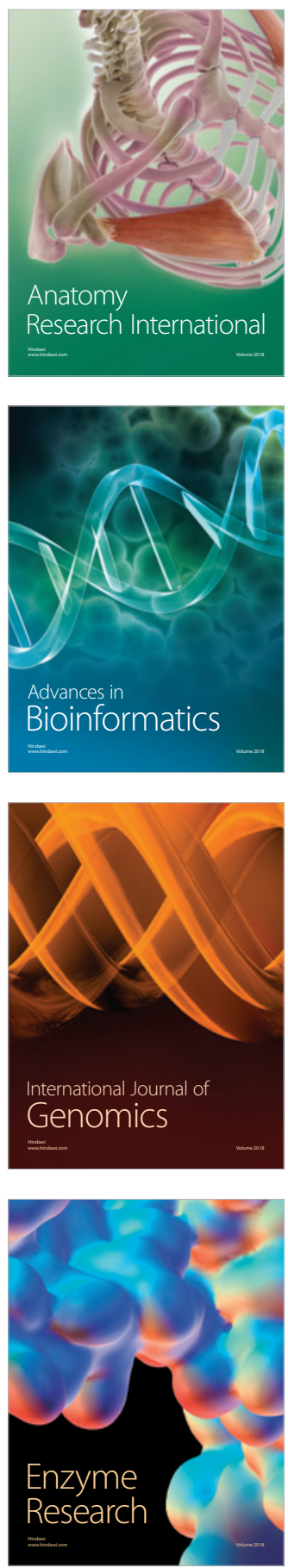
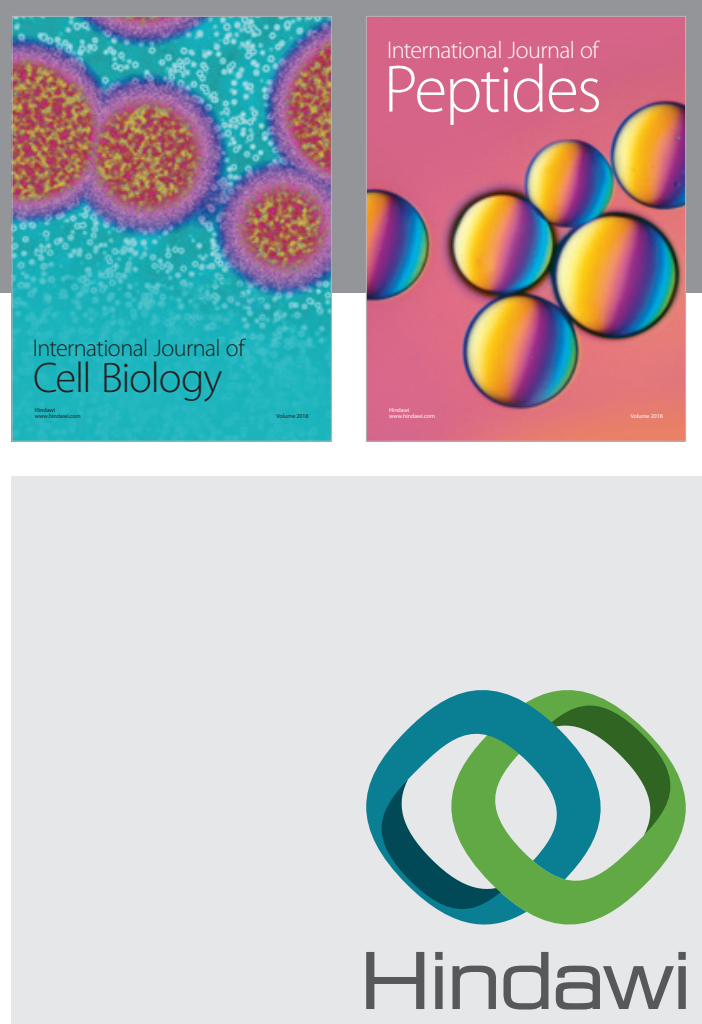

Submit your manuscripts at

www.hindawi.com
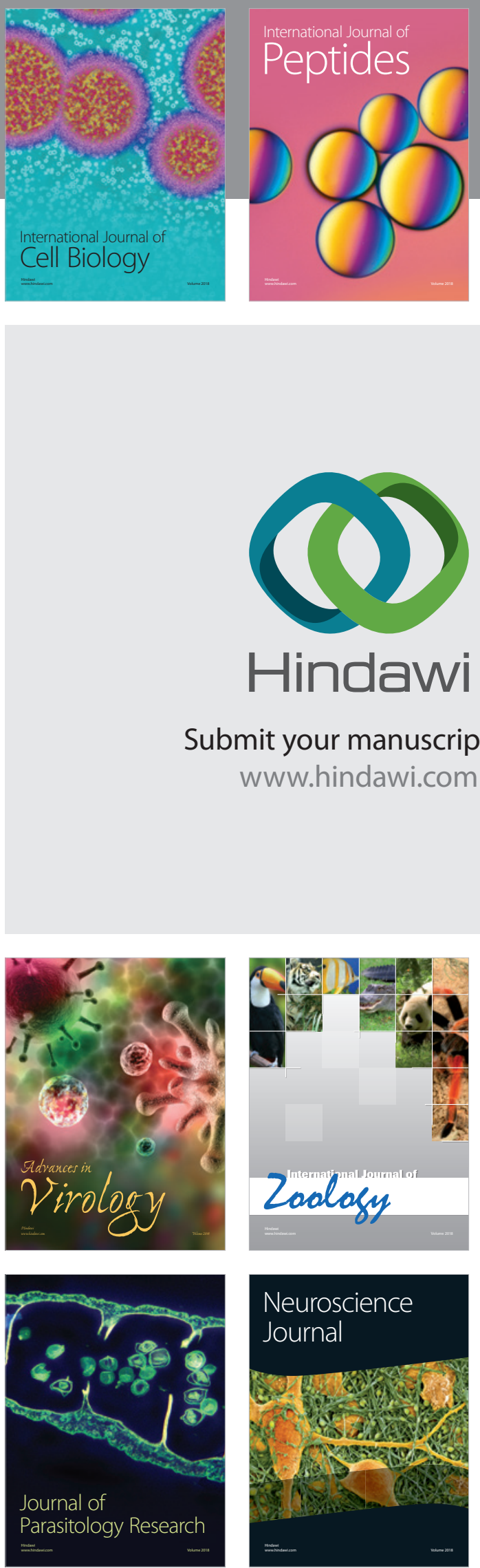
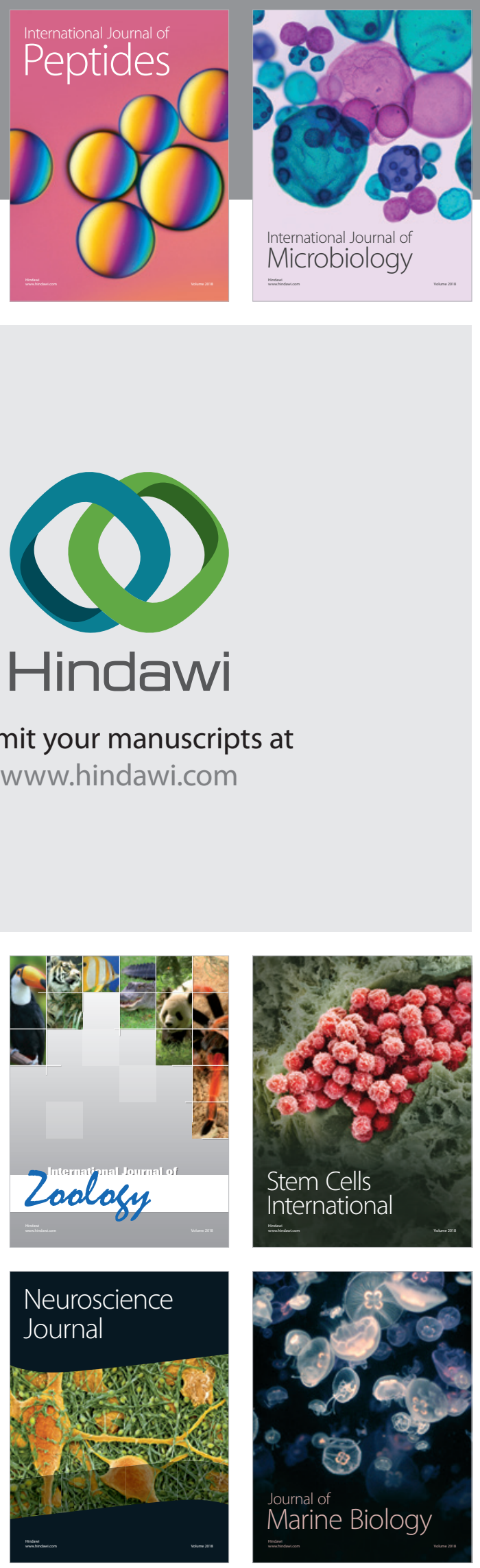
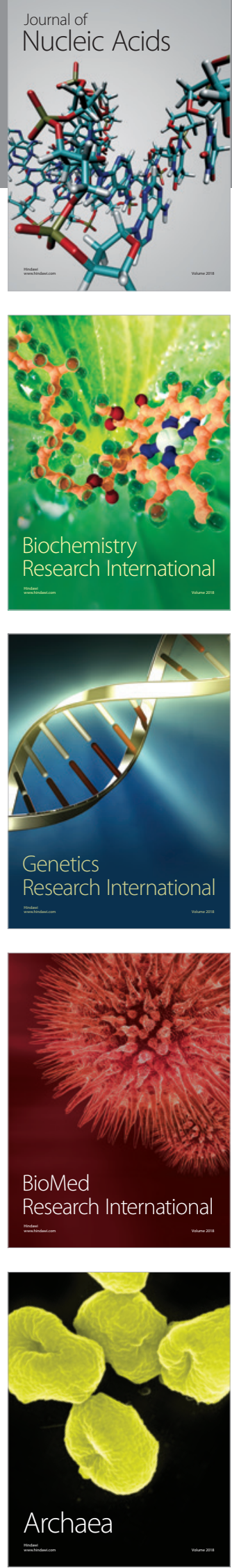